\title{
Borehole enlargement rate as a measure of borehole instability in hydrate reservoir and its relationship with drilling mud density
}

\author{
Qingchao $\mathrm{Li}^{1,2}$ (1) $\cdot$ Lingling $\mathrm{Liu}^{3} \cdot$ Baohai $\mathrm{Yu}^{4} \cdot$ Linian $\mathrm{Guo}^{3} \cdot$ Sheng $\mathrm{Shi}^{4} \cdot \mathrm{Linchun} \mathrm{Miao}^{4}$
}

Received: 7 October 2020 / Accepted: 21 January 2021

(c) The Author(s) 2021

\begin{abstract}
Borehole collapse will pose a threat to the safety of equipment and personnel during drilling operation. In this paper, a finite element multi-field coupling model for investigating borehole collapse in hydrate reservoir was developed. In this model, fluid seepage, heat transfer, hydrate dissociation and borehole deformation are all considered. Based on which, effects of drilling fluid density on both of hydrate dissociation and borehole collapse are investigated. The investigation results show that disturbance of drilling fluid invasion to hydrate reservoir will lead to hydrate dissociation around wellbore, and dissociation range narrows obviously with the increase in drilling fluid density. When the relative fluid density is 0.98 , natural gas hydrates in reservoir with a width of about $16.65 \mathrm{~cm}$ around wellbore dissociate completely. However, dissociation range of natural gas hydrate has decreased to $12.08 \mathrm{~cm}$ when the relative fluid density is 1.10 . Moreover, hydrate dissociation around wellbore caused by drilling fluid invasion may lead to borehole collapse, and borehole collapse can be significantly restrained with the increase in relative fluid density. Borehole enlargement rate is $33.67 \%$ when the relative fluid density is 0.98 , but nearly no collapse area displays around wellbore when the relative fluid density increases to 1.12. In addition, investigation herein can provide an idea for designing drilling fluid density in hydrate reservoir when different allowable borehole enlargement rate is considered. The minimum fluid density designed for avoiding disastrous borehole collapse increases nonlinearly when higher requirements for borehole stability are proposed.
\end{abstract}

Keywords Drilling fluid density $\cdot$ Drilling fluid invasion $\cdot$ Hydrate dissociation $\cdot$ Borehole collapse $\cdot$ Borehole enlargement rate $\cdot$ South China Sea

\section{Introduction}

Natural gas hydrates are crystals mainly composed of gas molecules (such as methane) and water molecules (Sloan 1998; Klar et al. 2010; Lu 2015; Gai and Sánchez 2017; Zhao et al. 2019). Appropriate temperature and pressure conditions in reservoir and sufficient gas source are three

Qingchao Li

liqingchao2020@hpu.edu.cn

1 School of Energy Science and Engineering, Henan Polytechnic University, Henan 454000, Jiaozuo, China

2 School of Petroleum Engineering, China University of Petroleum (East China), Qingdao 266580, Shandong, China

3 Petrochina Changqing Oilfield Company Oil Production Plant No. 10, Xian 710000, China

4 Petrochina Changqing Oilfield Company Oil Production Plant No. 7, Xian 710000, China important factors affecting the formation of hydrates in nature (Klar et al. 2010; Lu 2015; Gai and Sánchez 2017). Due to the fact that natural gas hydrates can ease the potential energy crisis, in-depth investigations on production strategies of natural gas hydrates have been conducted. At present, the total reserves of natural gas hydrates in the world have not be unified due to the difference in statistical methods. However, it is generally recognized that the organic carbon stored in natural gas hydrates is more than twice that of conventional energy sources (Milkov 2004; Li et al. 2013; Merey 2016; Zhang et al. 2017a, b). Therefore, if natural gas hydrates can be commercially developed, they have the potential to become a mainstream energy to replace the conventional energy sources in the near future. However, only the laboratory experiments and/or the numerical simulation related to natural gas hydrates can be carried out now, and the implementation of field experiments is still somewhat difficult. 
Strength of hydrate-bearing sediments in natural environment is usually very low, and various engineering geological hazards will arise during its development (Rutqvist and Moridis 2007; Li et al. 2011; Uchida et al. 2012; Klar et al. 2013; Cha et al. 2016). Moreover, hydrate dissociation during natural gas production from hydrate reservoirs may aggravate the occurrence of these geological hazards. Effect of hydrate dissociation on hydrate-bearing sediments can be clearly illustrated by Fig. 1. As is illustrated in Fig. 1, even for hydrate-bearing sediments with higher hydrate saturation, it still looks soft. Let alone the deposits after hydrate dissociation, it looks like fluid.

It is known that hydrate dissociation in the near-wellbore region is fatal to borehole stability during drilling in hydrate reservoir (Tan et al. 2005; Qiu et al. 2015; Ning et al. 2013a, b; Fereidounpour and Vatani 2014, 2015; Matsuda et al. 2016; McConnell et al. 2012). Reservoir temperature and pore pressure are the two most important factors affecting the stability of natural gas hydrate. However, hydrate dissociation within the near-wellbore region will occur violently due to the disturbance of drilling fluid during drilling operation, resulting in borehole collapse (Li et al. 2018a). Disturbances of pore pressure and temperature within the near-wellbore region caused by drilling fluid invasion mainly depend on drilling fluid density and fluid temperature, respectively. Therefore, thorough analysis of drilling fluid invasion and its impact on borehole stability during drilling operation in hydrate reservoir is important to the safe and efficient development of natural gas hydrates.

Up to now, most of the relevant experimental studies are focused on exploring ways to inhibit hydrate formation within wellbore during drilling operation (Zhao et al. 2015; Zhao et al. 2020; Liu et al. 2016; Mech and Sangwai 2016). Few works have been carried out for investigating the interaction between drilling fluid and hydrate reservoir, let alone wellbore instability caused by drilling fluid invasion. In addition, some researchers have done some numerical investigations on borehole stability during the drilling operation in hydrate reservoir. Tan et al. (2005) presented the requirements to develop a comprehensive risk management capability for drilling in gas hydrate-bearing sediments. And,

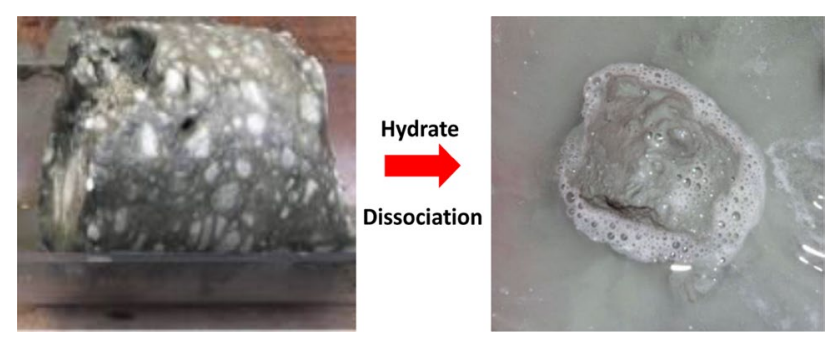

Fig.1 Photo of natural hydrate deposit before and after dissociation in the South China Sea the methodology reducing risk and uncertainty of wellbore stability associated with gas hydrates in deep water during hydrate development was also investigated. Qiu et al. (2015) proposed a new workflow to carry out the investigation of wellbore integrity for a methane hydrate production test well in the Nankai Trough. Moreover, the effect of cement bond quality on the wellbore integrity during hydrate development was also conducted. Li et al. (2018a) developed the investigation method and finite element model for analyzing borehole stability in hydrate-bearing sediments with ABAQUS software. It has been verified that the established model has good accuracy and applicability. In a word, all these studies are valuable for analyzing collapse behavior of borehole during drilling in hydrate reservoir. However, few in-depth analyses specifically aimed at the effect of drilling fluid density on borehole collapse have been launched, not to mention the corresponding mechanism analysis and engineering guidance.

In the present work, the finite element model that integrated seepage, heat transfer, hydrate dissociation and borehole deformation was developed. With this model, disturbance of drilling fluid to hydrate-bearing sediment around wellbore was then investigated. Moreover, effects of drilling fluid density on borehole collapse associated with drilling operation in hydrate-bearing sediments were analyzed. Finally, the method for determining the minimum fluid density with considering different acceptable borehole enlargement rate is obtained. The investigation results herein can provide reference and support for the drilling fluid design while drilling in hydrate reservoir.

\section{Study area}

With an area of about 3.5 million square kilometers, the South China Sea undoubtedly becomes the largest marginal sea in the Western Pacific. Water depth in the northern South China Sea is mostly between 500 and $3500 \mathrm{~m}$, with an average water depth of $1350 \mathrm{~m}$. Such deep-water environment provides favorable temperature and pressure conditions for the formation and existence of natural gas hydrate. Figure 2 shows the location and geological setting of the Shenhu area in the northern South China Sea. As can be seen from Fig. 2, the Shenhu area is located in the Zhu II depression of the Pearl River Mouth Basin in the Northern South China Sea, and it is the main area for the exploration of natural gas hydrate for China (Wan et al. 2017).

Although China started late in its hydrate-related exploration or development activities in the South China Sea, it has made rapid progress in the present years. In 1998, China Geological Survey officially conducted the first exploration of natural gas hydrate in the South China Sea. Subsequently, China Geological Survey organized four activities for 
Fig.2 Geological setting of the study area (revised from $\mathrm{Wu}$ and Wang 2018)

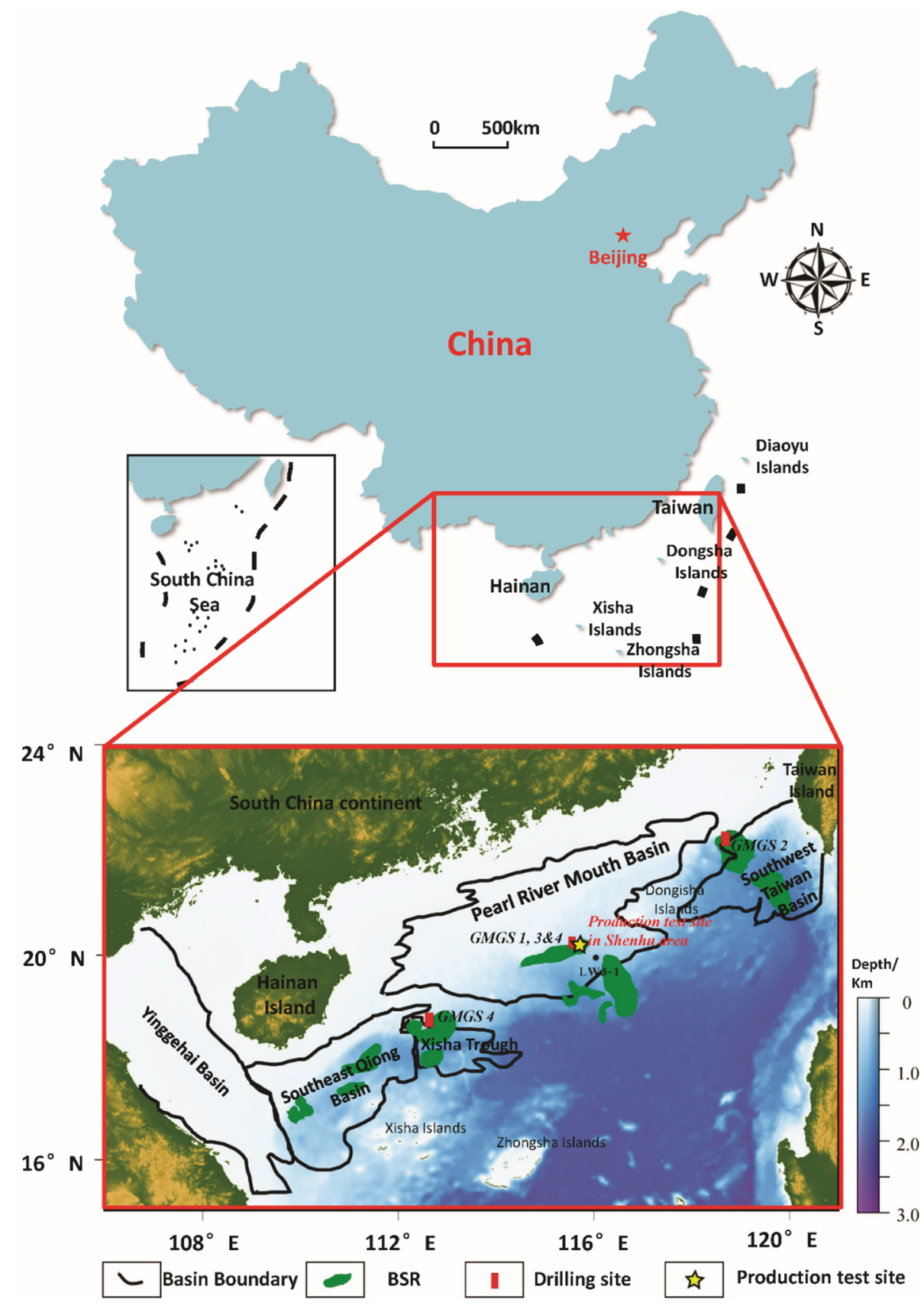

exploring gas hydrate in 2007, 2013, 2015 and 2016, respectively, in the South China Sea. After more than 20 years of exploration, it is found that there are abundant hydrate resources in the South China Sea. Therefore, Guangzhou Marine Geological Survey conducted two production tests in this area in 2017 and 2020, and the gas production rates of the two production tests were $5000 \mathrm{~m}^{3} /$ day and $28700 \mathrm{~m}^{3} /$ day in average, respectively. Although these two production tests have achieved great success compared with that in other countries, production practice proved that underground accidents such as borehole collapse are still important issues affecting efficient development of natural gas hydrates.
Therefore, in the present work, site of GMGS(2007)-SH2 is taken as the example for investigating borehole collapse in hydrate reservoir.

\section{Investigation model}

Borehole collapse occurred in hydrate reservoir is a complex physical phenomenon involving drilling fluid invasion, hydrate dissociation and strata deformation. Development of the corresponding simulation model on ABAQUS platform includes (1) defining model geometry, (2) defining 
material properties and constitutive model, (3) discretizing the numerical model into elements, (4) specifying loads, boundary conditions and initial conditions.

\section{Model geometry}

The established 2D coupled finite element model that used for investigating the effects of drilling fluid density on borehole collapse is displayed as Fig. 3. It can be seen from Fig. 3a that water depth is $1235 \mathrm{~m}$ at site GMGS(2007)$\mathrm{SH} 2$, and the thicknesses of overlying formation and hydrate reservoir are $195 \mathrm{~m}$ and $25 \mathrm{~m}$, respectively. The investigation model adopted in this work is chosen at the depth of $210 \mathrm{~m}$ below seafloor, which is approximately the middle depth of the hydrate layer. In addition, it is assumed that the 8.5 inch drill bit is used in the drilling operation of hydrate layer. Therefore, borehole in the model is assumed to be an uncased vertical one (see Fig. 3b) with a radius of $0.216 \mathrm{~m}$. Moreover, considering the fact that hydrate dissociation during drilling operation only occurs within the near-wellbore region, the model radius is designed to be $20 \mathrm{~m}$.

After model discretization, there are a total of 16,250 stress/pore pressure elements (CPE4P) in the investigation model (see Fig. 3c). All elements included in model can efficiently simulate the drilling fluid invasion, hydrate dissociation and borehole collapse during drilling in hydrate reservoir. Since hydrate dissociation mainly occurs within the near-wellbore region, elements are denser in this area than other region after mesh refinement. There are 8024 elements within the near-wellbore region after discretization, which accounts for about half of the elements in the whole model. It is worth noting that the element size within the model displayed in Fig. 3 is determined after evaluation and optimization.

\section{Simulation steps and boundary conditions}

Ideally, hydrate reservoir in natural environment should be undisturbed by any artificial activities. In this case, the established model should be a plane strain model without borehole. However, in order to reduce the number of elements within the model to speed up the simulation, the borehole has been directly presented herein. In this case, the normal displacement of borehole needs to be constrained at the initial moment of simulation, then release it and apply drilling fluid pressure on borehole to complete the subsequent work. Therefore, simulation needs to be implemented by two consecutive analysis steps: Geostatic step and Borehole Collapse step, and the analysis time of two steps is $1 \mathrm{~s}$ and $14400 \mathrm{~s}$, respectively. The aim of the Geostatic step is to obtain the initial properties of reservoir, which can provide a basis for subsequent simulation. In the Borehole Collapse
Fig.3 Schematic of borehole stability model during drilling operation in hydrate reservoir. a Wellbore trajectory and wellbore structure; $\mathbf{b}$ the model geometry and the model size; c Mesh model for simulating hydrate dissociation and borehole collapse in hydrate-bearing sediments

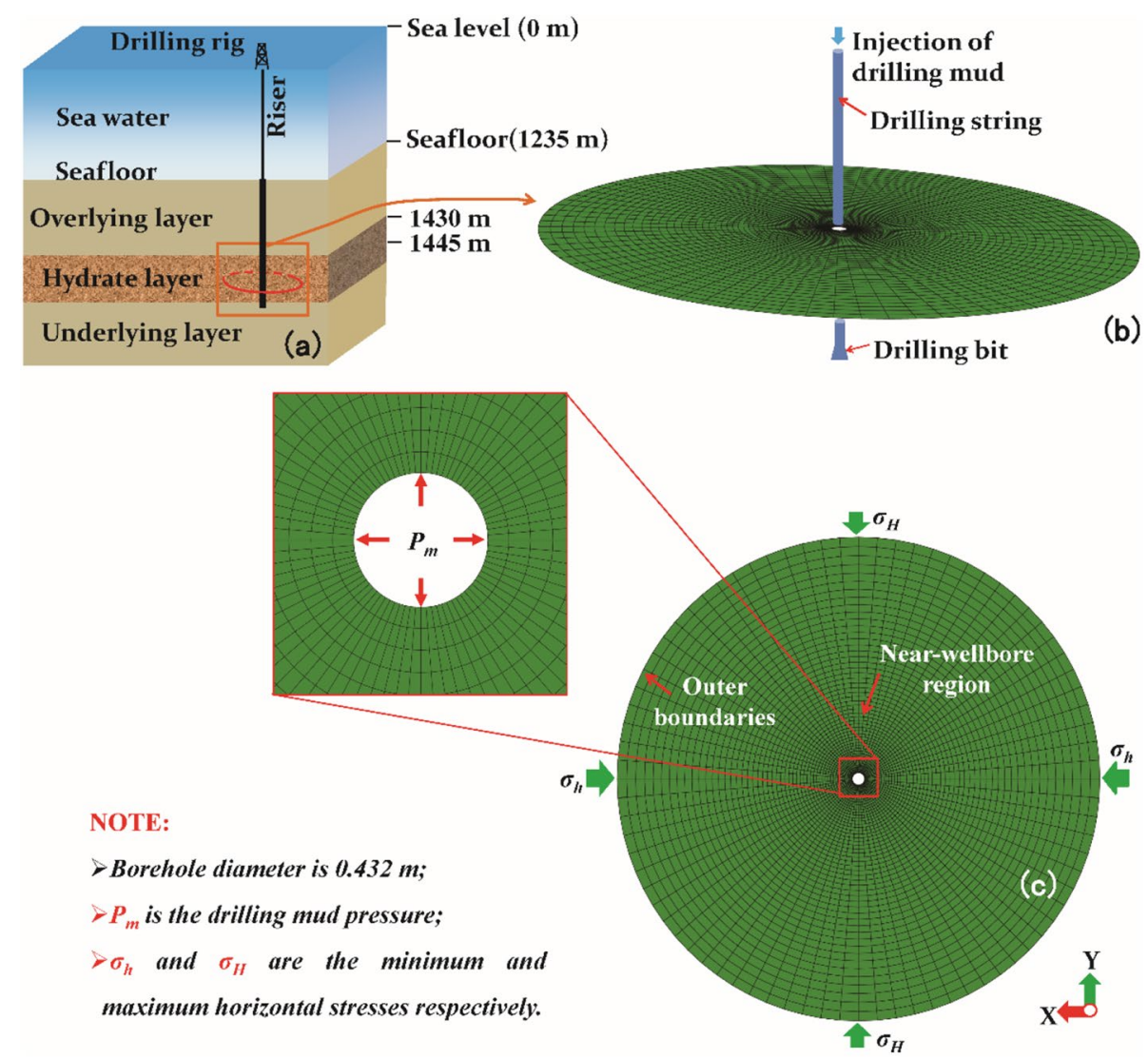


step, simulations of fluid invasion, hydrate dissociation and borehole collapse should be completed. All boundary conditions have been shown in Table 1. In Table 1, the ticks $(\sqrt{ })$ indicate that these boundary condition has been applied in corresponding analysis step, while the blank indicates that these boundary condition has not been applied.

Loads need to be applied herein are the drilling fluid pressure. Drilling fluid pressure is the integral of the drilling fluid density along the vertical depth, and pore pressure is the integral of the sea water density along the vertical depth. For the convenience of subsequent investigation, parameter of relative fluid density $P_{c}$ is defined as the ratio of drilling fluid pressure to pore pressure. For example, the drilling fluid pressure and pore pressure are equal to each other if the fluid relative density is 1.00 . Considering the fact that high drilling fluid pressure on borehole may not result in borehole collapse, and can only result in hydrate dissociation. So, the range of relative fluid density herein is chosen from 0.98 to 1.12. Moreover, considering that the Mohr-Coulomb criterion is one of the most commonly used yield criterions, so all numerical simulations in the present work are based on the Mohr-Coulomb criterion.

Only when the numerical simulation relies on the field data as much as possible, can it provide a specified reference for field construction. The basic input data for investigation of borehole stability in silt hydrate-bearing sediments at site GMGS(2007)-SH2 herein are listed in Table 2 (Wu et al. 2010; Wang et al. 2011; Xiao et al. 2013; Liu et al. 2017; $\mathrm{Li}$ et al. 2018b). It should be stated that all parameters in Table 2 are all obtained from the open literature.

\section{Change of physical parameters with hydrate dissociation}

Properties of hydrate-bearing sediments will change with hydrate dissociation caused by invasion of drilling fluid in hydrate reservoir. However, there is no uniform model to describe the property variation of hydrate-bearing sediments during hydrate dissociation now. Therefore, some empirical formulae describing the relationship between properties of hydrate-bearing sediments and hydrate saturation have been obtained based on some experimental investigation (Cha et al. 2016).

Considering the fact that borehole deforms large within the near-wellbore region during the whole simulation, the Mohr-Coulomb failure criterion is used herein. Therefore, evolution equation of mechanical properties such as Young's modulus and cohesion of hydrate reservoir during drilling operation should be given. The relationship between Young's modulus of hydrate-bearing sediments and hydrate saturation can be expressed by Eq. (1).

$E=125+1000 \cdot S_{\mathrm{h}}$

where $E$ is the Young's modulus of hydrate-bearing sediments in MPa when the hydrate saturation is $S_{h}$.

Some investigations have shown that Poisson's ratio of hydrate-bearing sediment varies little with hydrate dissociation. Therefore, it is assumed that no change occurs in Poisson's ratio of hydrate-bearing sediment within the nearwellbore region during the whole drilling operation herein.
Table 1 All the boundary conditions in different simulation steps

\begin{tabular}{|c|c|c|c|c|c|c|}
\hline \multirow{2}{*}{$\begin{array}{l}\text { Step No } \\
\text { Boundary Type }\end{array}$} & \multicolumn{3}{|c|}{ Geostatic step (1 s) } & \multicolumn{3}{|c|}{ Borehole collapse step (14400 s) } \\
\hline & Displacement & Temperature & Pore pressure & Displacement & Temperature & Pore pressure \\
\hline Outer boundary & $\sqrt{ }$ & & & $\sqrt{ }$ & $\sqrt{ }$ & \\
\hline Borehole & $\sqrt{ }$ & & & & $\sqrt{ }$ & $\sqrt{ }$ \\
\hline
\end{tabular}

Table 2 Physical parameters of hydrate reservoir at site GMGS(2007)-SH2 and the drilling conditions

\begin{tabular}{|c|c|c|c|c|c|}
\hline Parameter & Value & Unit & Parameter & Value & Unit \\
\hline Density, $\rho$ & 2000 & $\mathrm{Kg} / \mathrm{m}^{3}$ & Thermal conductivity, $\lambda$ & 1.308 & $\mathrm{~W} /(\mathrm{m} \cdot \mathrm{K})$ \\
\hline Young's modulus, $E_{0}$ & 625 & $\mathrm{MPa}$ & Specific heat capacity, $C_{s h}$ & 1362 & $\mathrm{~J} /(\mathrm{Kg} \cdot \mathrm{K})$ \\
\hline Initial dilation angle, $\psi$ & 17.46 & $\circ$ & Relative fluid density, $P_{c}$ & $0.98 \sim 1.12$ & MPa \\
\hline Poisson's ratio, $v_{0}$ & 0.35 & - & Fluid temperature, $T_{m}$ & 21.25 & ${ }^{\circ} \mathrm{C}$ \\
\hline Friction angle, $\epsilon$ & 23 & $\circ$ & Drilling time, $t_{d}$ & 4 & $\mathrm{~h}$ \\
\hline Initial cohesion, $C_{0}$ & 1.035 & $\mathrm{MPa}$ & Initial porosity, $\phi_{0}$ & 52.46 & $\%$ \\
\hline Void ratio & 0.8512 & - & Hydrate saturation, $S_{h 0}$ & 41.40 & $\%$ \\
\hline Initial pore pressure, $P_{p i}$ & 14.586 & $\mathrm{MPa}$ & Max. horizontal stress, $\sigma_{H}$ & 2.25 & MPa \\
\hline Vertical effective stress, $\sigma_{V}$ & 1.96 & $\mathrm{MPa}$ & Min. horizontal stress, $\sigma_{h}$ & 1.75 & MPa \\
\hline Initial temperature, $T$ & 15.25 & ${ }^{\circ} \mathrm{C}$ & Density of sea water & 1030 & $\mathrm{Kg} / \mathrm{m}^{3}$ \\
\hline
\end{tabular}


The cohesion also changes with hydrate saturation, and relationship between cohesion and hydrate saturation can be expressed by the following equation:

$C=2.5 \times S_{\mathrm{h}}$

where $C$ is the cohesion of hydrate-bearing sediments in MPa when the hydrate saturation is $S_{h}$.

In addition, influence of hydrate saturation on the internal friction angle of hydrate-bearing sediment can be expressed by Eq. (3).

$\sin \psi=0.05+0.5 \times S_{\mathrm{h}}$

where $\psi$ is the dilation angle of hydrate-bearing sediments.

Permeability of hydrate-bearing sediment will also be affected by change of hydrate saturation during drilling operation, which can be described by the following equation (Sakamoto et al. 2010).

$K=K_{0} \cdot\left(1-S_{\mathrm{h}}\right)^{N}$

$N=10.384 \times S_{\mathrm{h}}^{2}-22.773 \times S_{\mathrm{h}}+13.639$

where $K_{0}$ is the initial permeability of hydrate-bearing sediment, $N$ is a variable related to hydrate saturation.

Hydrate dissociation around the wellbore and the resulting changes in sediment physical parameters are realized by USDFLD subroutine during simulation. The source code of USDFLD subroutine is shown in Appendix A.

\section{Determination of hydrate saturation}

Herein, the phase equilibrium curve of methane hydrate in sea water is used to determine whether hydrate will dissociate. The phase equilibrium equation curves of pure methane hydrate can be written as follows (Nazridoust and Ahmadi 2007):

$\lg \left(P_{\text {eq }}\right)=0.034 T_{\text {eq }}+0.0005 T_{\text {eq }}^{2}+6.4804$

where $P_{e q}$ is the phase equilibrium pressure, and $T_{e q}$ is the phase equilibrium pressure.

As shown in Fig. 4, the phase equilibrium curve of methane hydrate was obtained according to Eq. (5). Based on this, the stability of methane hydrate at any temperature and pressure can be judged. We can know from Fig. 4 that natural gas hydrates are stable in natural state. However, although the highest relative fluid density is 1.10 , hydrates become extremely unstable when the drilling fluid temperature is $21.25^{\circ} \mathrm{C}$. That is, disturbance of drilling fluid may make natural gas hydrates around the wellbore begins to dissociate. Although Eq. (5) can be used to determine whether hydrates dissociation can occur at certain temperature and pore

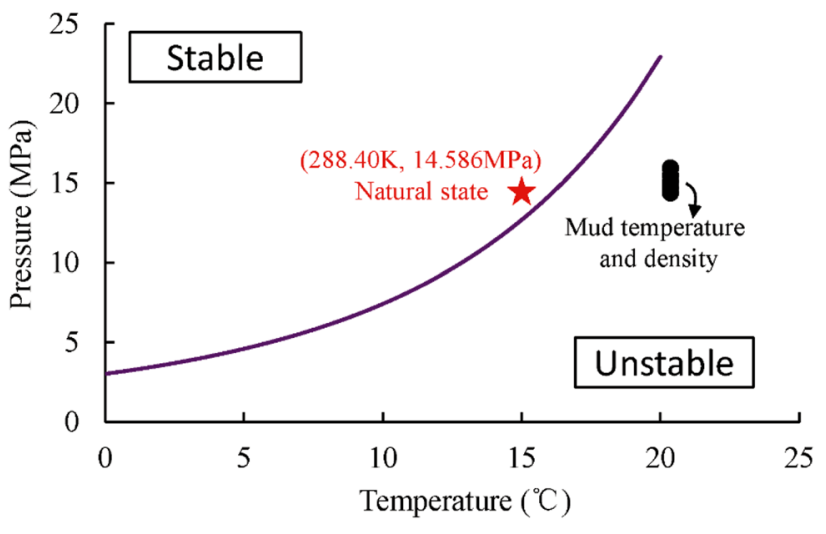

Fig.4 Phase equilibrium curve of methane hydrate

pressure, dissociation degree of methane hydrate still needs to be achieved by the kinetic equation shown in Eq. (6).

$m_{g}=K_{\mathrm{rd}} M_{g} A_{\mathrm{dec}} \varphi S_{\mathrm{h}}\left(f_{e}-f_{\mathrm{g}}\right)$

where $m_{g}$ is gas production rate from hydrate dissociation, $K_{r d}$ is the hydrate dissociation constant, $M_{g}$ is the molecular mass of methane, $A_{d e c}$ is the surface area hydrate in unit volume, $\varphi$ is porosity of hydrate reservoir, $f_{e}$ and $f_{g}$ are fugacity of methane at equilibrium pressure and gas phase pressure, respectively.

\section{Model validation}

In this section, the applicability of the numerical simulation model used in the present work is verified by the drilling fluid disturbance experiments.

As we all know, when there are differences in the material composition of hydrate-bearing sediments, the measurement results of acoustic wave velocity will also be significantly different. Therefore, the change of acoustic wave velocity can be used to judge whether hydrate dissociates during the experiments. Herein, the influence of drilling fluid on natural gas hydrate within the near-wellbore region is investigated by the drilling fluid disturbance experimental system. The main component of the experimental system is the highpressure cylinder, which can withstand high pressures up to $100 \mathrm{MPa}$. Figure 5 shows the structure of high-pressure cylinder in the experimental system. As shown in Fig. 5, the high-pressure cylinder is a cylinder with the length of $100 \mathrm{~cm}$ and the radius of $10 \mathrm{~cm}$. In addition, three acoustic probes are set along the radial direction of the high-pressure cylinder according to a certain distance (it is $20 \mathrm{~cm}$ herein), which are used for measurement of acoustic wave velocity during experiment.

Before the experiment, the high-pressure cylinder was filled with hydrate-bearing sediments with hydrate saturation 


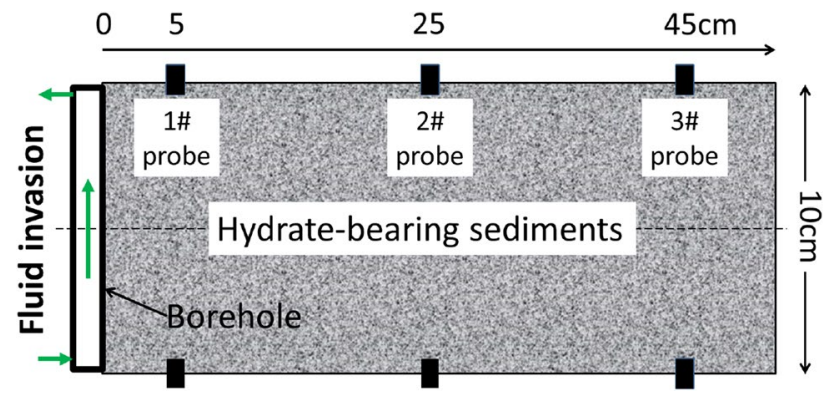

Fig.5 High-pressure cylinder in the experimental system

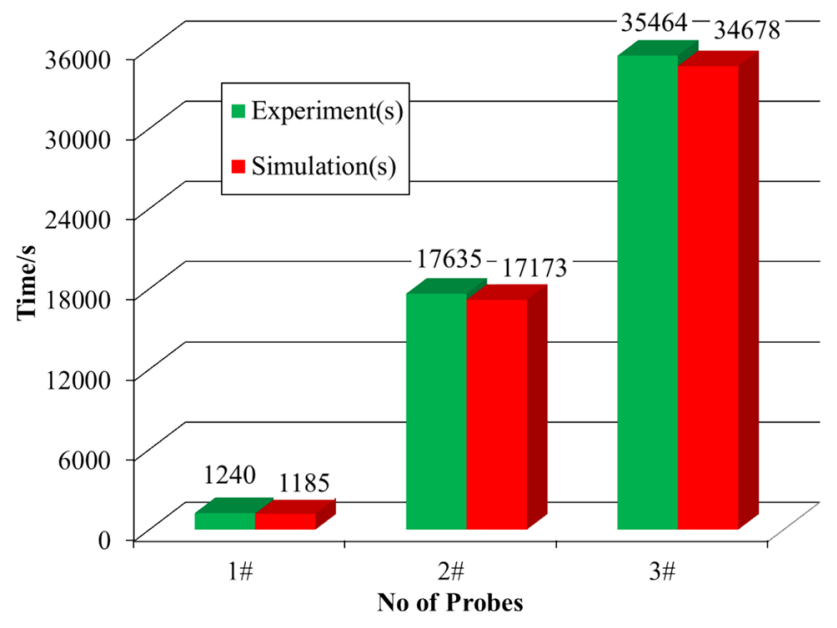

Fig.6 High-pressure cylinder in the experimental system

of 0.414. During the experiment, the drilling fluid with certain temperature $\left(25.25^{\circ} \mathrm{C}\right)$ and pressure $(14.586 \mathrm{MPa})$ continuously circulates through one end of the high-pressure cylinder (left end in Fig. 5). Since the high-pressure cylinder is always placed in cold storage, its temperature will always be maintained at $15.25{ }^{\circ} \mathrm{C}$. In addition, the pressure in cylinder needs to be maintained at $14.586 \mathrm{MPa}$ with the help of servo-controlled pump during the experiments. At the same time, three acoustic probes can real-timely collect the acoustic wave velocity at different positions of high-pressure cylinder at $5 \mathrm{~min}$ intervals during the experiment, so as to judge the dissociation of natural gas hydrate at the corresponding position.

According to the above experimental conditions, the corresponding mathematical simulation is also conducted by the established simulation model. During simulation, the properties of hydrate-bearing sediments are shown in Table 2. After processing the experimental results of wave velocity, Fig. 6 shows the comparison of the time required for natural gas hydrates to dissociate to three probes during experiment and numerical simulation. We can clearly see from Fig. 6 that although the numerical simulation results are all slightly smaller than the experimental results when hydrates dissociated to any probe position, the difference is small. Taking the 1\# probe (its position can be seen from Fig. 5) as an example, the time required for experiment and simulation is $1240 \mathrm{~s}$ and $1185 \mathrm{~s}$, respectively, when natural gas hydrate dissociates to this position. The experimental result is only $55 \mathrm{~s}$ longer than the simulation result. When natural gas hydrate dissociates to $3 \#$ probe, the time required for experiment and simulation is $35464 \mathrm{~s}$ and $34678 \mathrm{~s}$, respectively, the difference is only $786 \mathrm{~s}$. Therefore, it can be concluded that the numerical model established herein can be used for analyzing the influence of drilling fluid density on hydrate dissociation around wellbore and borehole instability during drilling in hydrate-bearing sediments.

\section{Results and discussions}

\section{Disturbance of drilling fluid invasion on temperature and pore pressure}

Disturbance of drilling fluid invasion on hydrate reservoir is manifested by changes of temperature and pore pressure within the near-wellbore region. Figure 7 displays the distribution of reservoir temperature within the near-wellbore region at different drilling time. White numbers in Fig. 7 represent the position of temperature front at different times. From Fig. 7, we can see that the temperature disturbance front gradually advances along the radical direction throughout the drilling operation. However, the advancement rate of temperature front decreases with the drilling operation. At the end of the drilling operation, temperature front is at the position of $0.506 \mathrm{~m}$ from borehole.

Pore pressure within the whole investigation model can also be affected by disturbance of drilling fluid. Figure 8 displays the evolution of pore pressure within the whole investigation model at different times when relative fluid density is 1.02. From the investigation results in Fig. 8, we can see that effect of drilling fluid on pore pressure within the model is greater than that on temperature. Correspondingly, pore pressure within nearly the whole model has been affected at the end of the drilling operation. Changes of both pore pressure and temperature within the whole model due to invasion of drilling fluid may result in hydrate dissociation in a large range of area around the wellbore. In the next section, hydrate dissociation caused by invasion of drilling fluid during drilling operation will be analyzed in detail.

\section{Hydrate dissociation caused by fluid invasion}

It is well known that methane hydrates are formed by water molecules and methane molecules at high temperatures and low pressures. Conversely, stability of natural gas hydrate 
Fig.7 Evolution of temperature distribution around wellbore during simulation when the fluid temperature is $21.25^{\circ} \mathrm{C}$
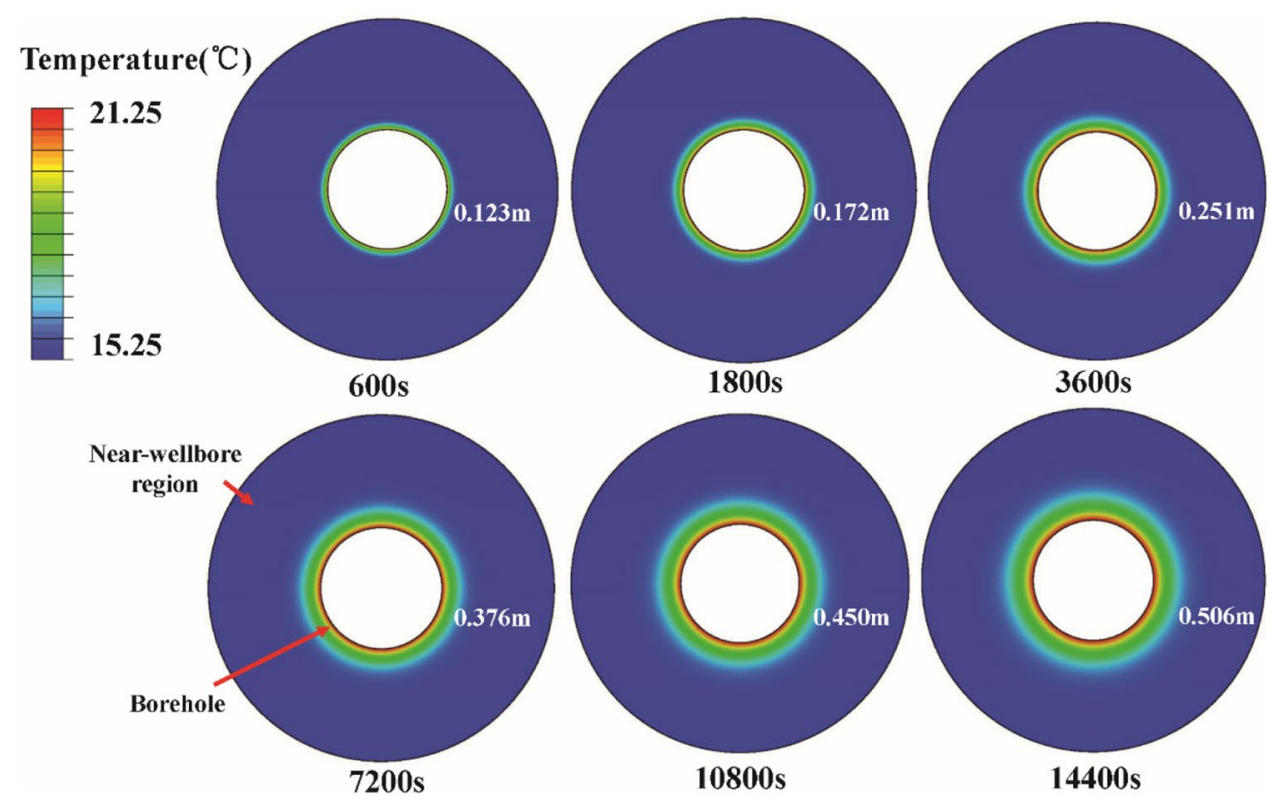

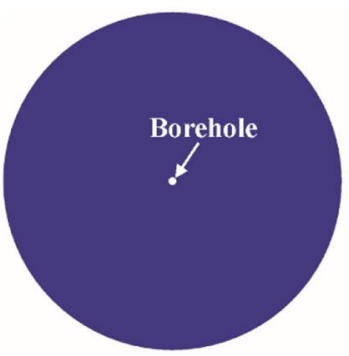

0s

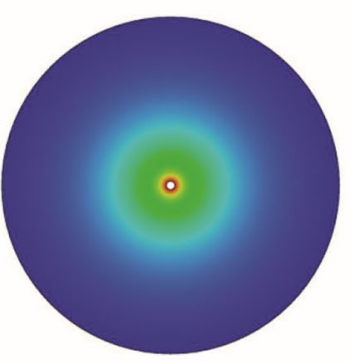

$7200 \mathrm{~s}$

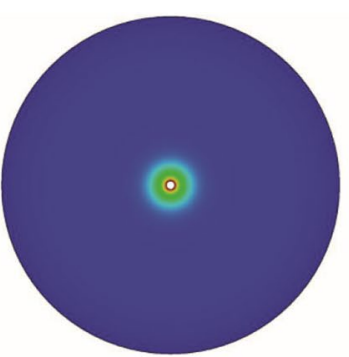

$600 \mathrm{~s}$

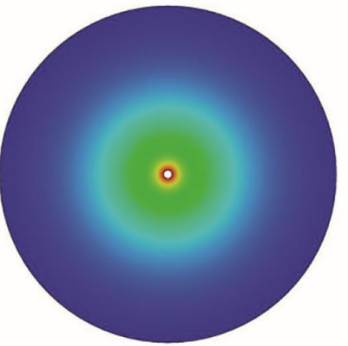

14400s

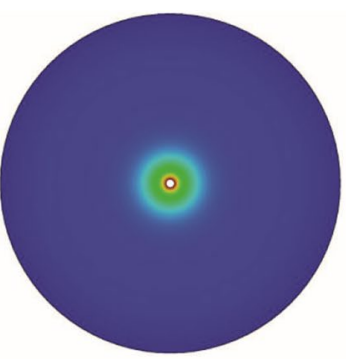

$600 \mathrm{~s}$

Pore Pressure, MPa

14.586

14.586

14.586

14.586 in the hydrate-bearing sediments will be threatened when reservoir temperature is higher than phase equilibrium temperature or/and pore pressure is lower than phase equilibrium pressure. Disturbance of drilling fluid occurred during the drilling operation is an important threat to the stability of natural gas hydrates within the porous media around wellbore.

Evolution curves of hydrate dissociation range around wellbore for different drilling fluid density are presented as Fig. 9. It can be seen from Fig. 9 that range of hydrate dissociation decreases with the increase in drilling fluid density at any time of the drilling operation. Natural gas hydrates in hydrate reservoir with a width of $12.08 \mathrm{~cm}$ around wellbore dissociate when the relative fluid density is 1.10 . However, dissociation range around wellbore has increased to $16.87 \mathrm{~cm}$ when the relative fluid density is 0.98 , which is about 1.40 times as wide as that at a relative fluid density of 1.10. This is for the reason that the stability of natural gas hydrate at low pore pressure is particularly weak. Therefore, the lower the drilling fluid density is, the more easily hydrate dissociation occurs.

The dissociation front depicted in Fig. 9 is defined as the position where the natural gas hydrate has just completely dissociated at any simulation time. In other words, 


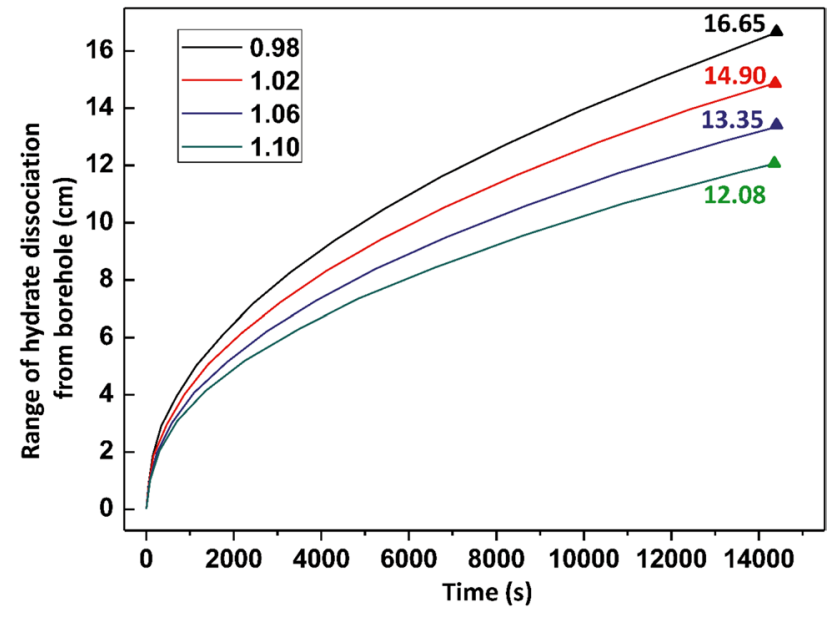

Fig.9 Effect of fluid density on hydrate dissociation caused by disturbance of drilling fluid during drilling in hydrate deposits

the dissociation front can be regarded as the junction of the dissociation region and the transition region at any time. However, hydrate dissociation is a very slow process, and the area near the dissociation front is not a cliff-like area where the hydrate saturation suddenly changes. A distinct transition region, in which hydrate saturation varies continuously from 0 to $41.40 \%$, exits between the dissociated region and the initial hydrate reservoir. Therefore, Fig. 10 presents distribution evolution of hydrate saturation within the nearwellbore region during the drilling operation for different relative fluid density. From Fig. 10, we can see that the width of dissociation transition region is always between $1.00 \mathrm{~cm}$ and $2.00 \mathrm{~cm}$ throughout the simulation, and is primarily related to the drilling fluid density. Moreover, we can also clearly see from Fig. 10 that the intervals between transition regions of hydrate saturation distribution curves for different fluid densities at the beginning of drilling operation are small. However, the intervals become so large at the end of drilling operation. So, the conclusion that hydrate dissociation will increase as the drilling fluid density decreases can also be indirectly drawn from Fig. 10.

\section{Collapse area around wellbore}

As mentioned above, equivalent plastic strain (PEEQ) is the physical variable used to determine the collapse position in investigation of engineering geology. It is considered that the area where the equivalent plastic strain occurs around wellbore may collapse in drilling operation. Herein, it is used to illustrate the collapse area around the vertical wellbore in hydrate-bearing sediments.

The potential collapse area (other areas except dark blue) during drilling operation in hydrate-bearing sediments under different drilling fluid density is presented as Fig. 11. As can be seen from Fig. 11, the collapse area is an elliptical area around wellbore, whose long axis coincides with the direction of the minimum horizontal principal stress. In addition, it can be qualitatively seen from Fig. 11 that the area of the collapse region around wellbore decreases with the drilling fluid density. However, the quantitative relationship between the potential collapse area around the wellbore and the relative fluid density cannot be determined by this. In order to solve this problem, parameter of the borehole enlargement rate $\varepsilon$ is defined herein and expressed by the following equation.

$\varepsilon=\frac{R_{\mathrm{mc}}-R_{w}}{R_{w}} \times 100 \%$

where $R_{m c}$ is the maximum radius of the collapse area around wellbore, and $R_{w}$ is the wellbore radius.

Figure 12 shows the quantitative relationship between borehole enlargement rate and relative fluid density when the temperature of drilling fluid is $21.25^{\circ} \mathrm{C}$. It can be seen from Fig. 12 that borehole enlargement rates decrease nonlinearly with relative fluid density. Borehole enlargement rate decreases rapidly with the increase in drilling fluid density when the relative fluid density is less than 1.03. However, when the relative fluid density is higher than 1.03, the rate at which the borehole enlargement rate decreases with the increase in fluid density has become extremely slow. Borehole enlargement rate caused by hydrate dissociation is $33.76 \%$ when the relative fluid density is 0.98 . However, borehole enlargement rate has reduced to $2.38 \%$ when the relative fluid density increased to 1.12 , which can be ignored in drilling engineering. The simulation result illustrates the impact of drilling fluid density on the borehole collapse is enormous. The reason for this can be explained by drilling fluid invasion and hydrate dissociation. On one hand, strength of hydrate deposit around wellbore can be greatly weakened by hydrate dissociation caused by disturbance of drilling fluid. For another, high effective stresses caused by hydrate dissociation and invasion of drilling fluid are also an important reason for borehole collapse. Therefore, with the increase in drilling fluid density, hydrate dissociation around wellbore will gradually weaken, resulting in slighter borehole collapse.

Polynomial showed in Eq. (8) can be used for describing the relationship between borehole enlargement rate and relative fluid density in the present work.

$\varepsilon(\%)=333.18-923.12 P_{c}+952.76 P_{c}^{2}-262.63 P_{c}^{3}$

With the help of Eq. (8), the effect of drilling fluid density on borehole collapse can be quantitatively evaluated.

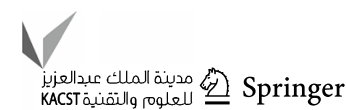




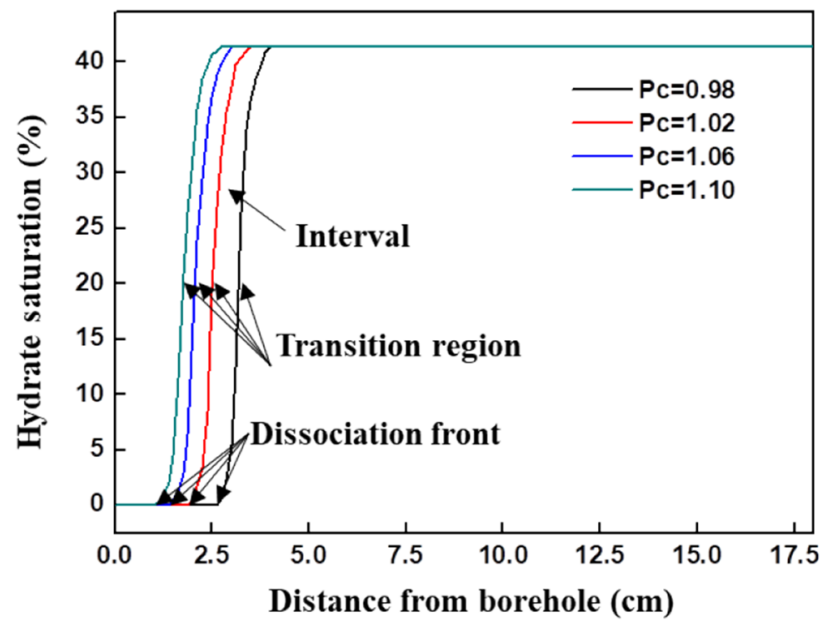

(a) $\mathrm{t}=600 \mathrm{~s}$

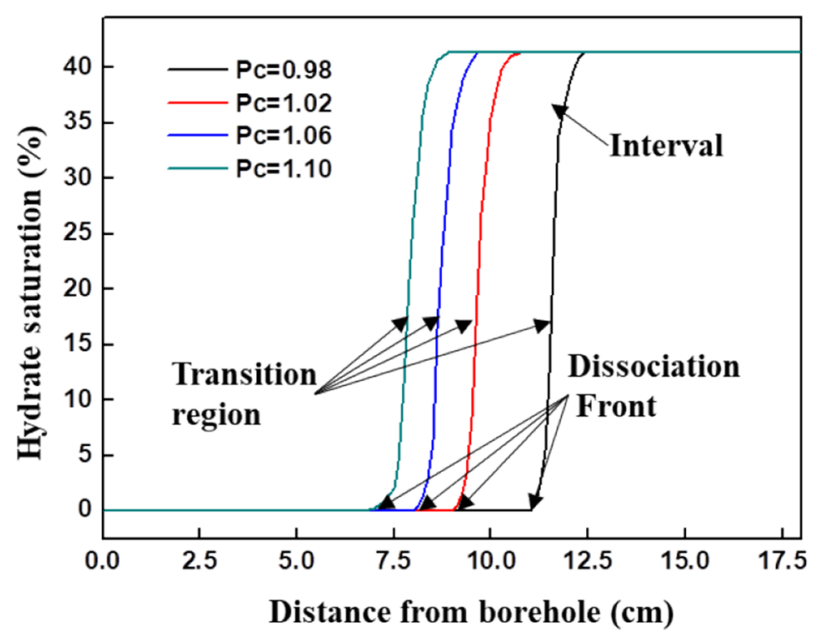

(c) $\mathbf{t}=\mathbf{7 2 0 0 s}$

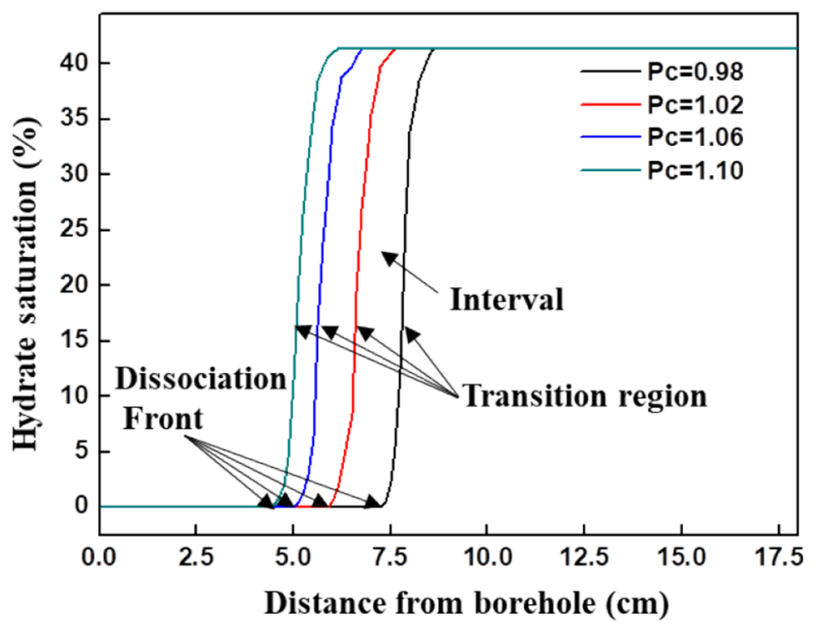

(b) $\mathrm{t}=3600 \mathrm{~s}$

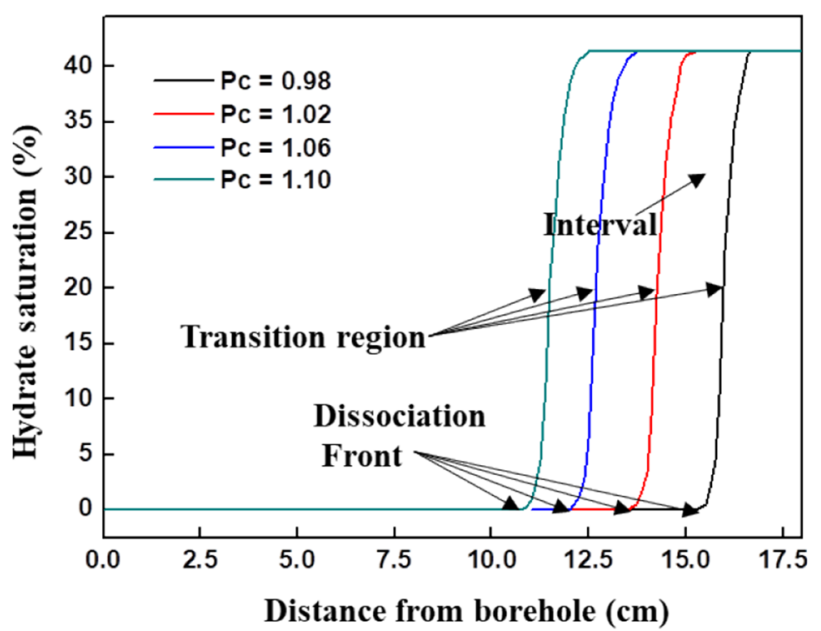

(d) $t=14400 \mathrm{~s}$

Fig.10 Distribution of hydrate saturation along a radial path at different times of drilling operation when the fluid density is different

\section{Design of fluid density in hydrate deposits}

As illustrated in Fig. 4, natural gas hydrate is stable in high pressure, but it will become unstable in low pressure. Therefore, according to the basic theory for wellbore stability, only the minimum drilling fluid density needs to be determined when hydrate deposits will not be fractured during drilling operation. Moreover, controllable borehole collapse during drilling operation in hydrate reservoir is permitted. Of course, it is best if the borehole collapse does not occur. Based on Eq. (8) and Fig. 12, a new method for determining the minimum fluid density in hydrate reservoir with considering different acceptable borehole enlargement rate is developed. Figure 13 shows the determination results of minimum fluid density in hydrate reservoir at site GMGS (2007)-SH2 with considering different acceptable borehole enlargement rates.

It can be seen from Fig. 13 that the required drilling fluid weight will be significantly increased with the increasing requirements for borehole integrity. When the acceptable enlargement rate of borehole is $2.5 \%$, the minimum fluid weight is 1.116 , which is a higher weight value for drilling operation in shallow layer in deep water area. However, as the decrease in requirements for borehole integrity, the minimum fluid weight decreases sharply. The minimum fluid weight reduced to 1.010 when the acceptable enlargement rate is decreased to $15 \%$. It is foreseeable that this phenomenon becomes more pronounced when the temperature of the drilling fluid is higher. 


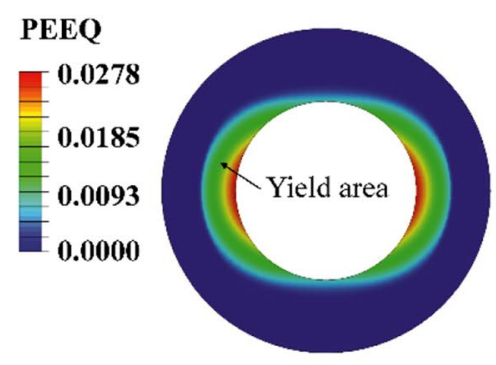

(a) $P_{c}=0.98$

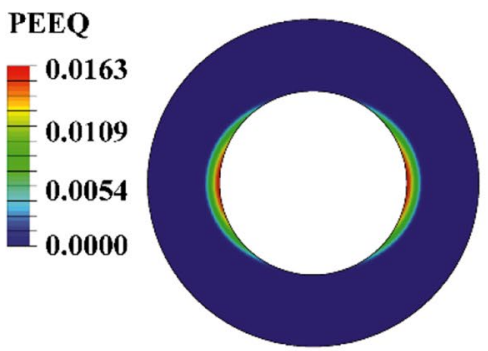

(d) $P_{c}=1.04$
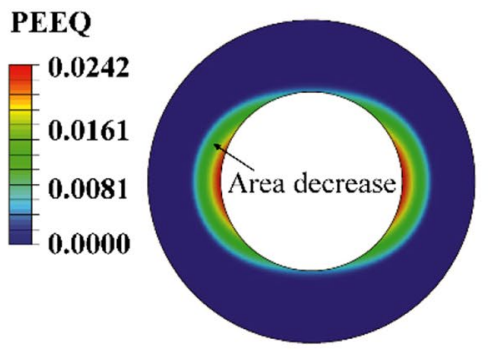

(b) $P_{c}=1.00$
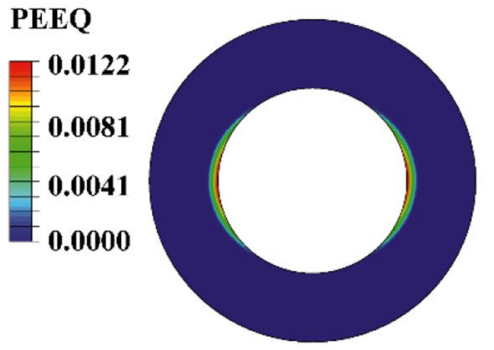

(e) $P_{c}=\mathbf{1 . 0 6}$

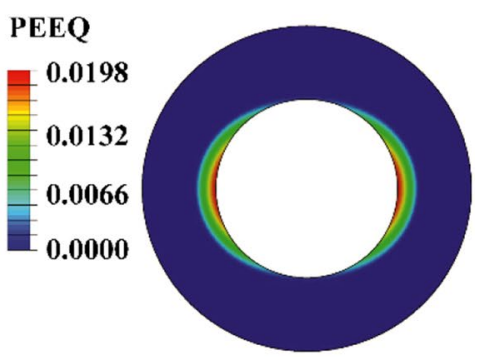

(c) $P_{c}=1.02$

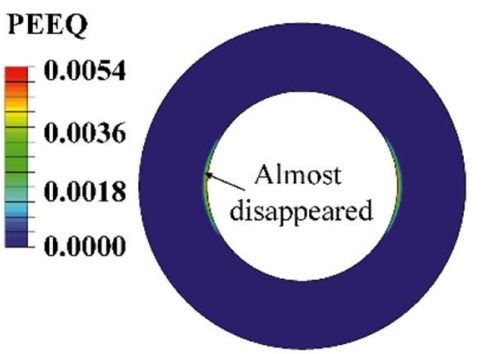

(f) $P_{c}=\mathbf{1 . 1 0}$

Fig.11 Equivalent plastic strain (PEEQ) within the near-wellbore region under different fluid density

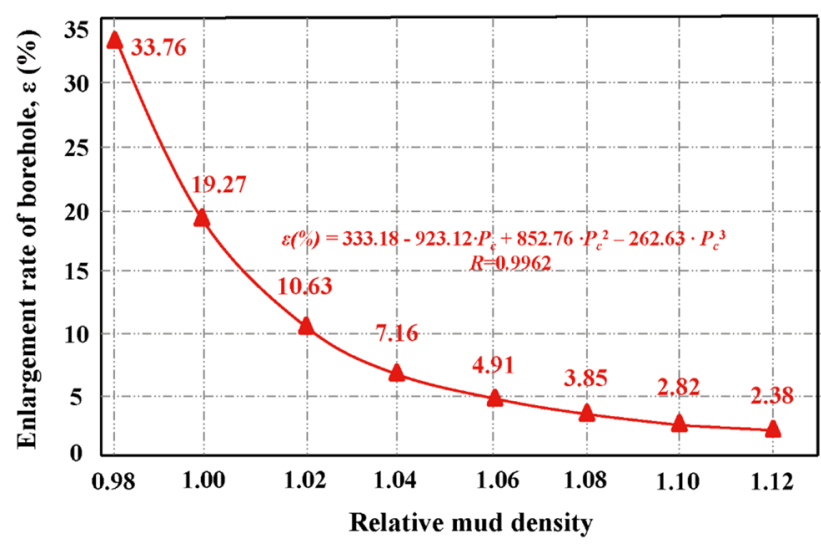

Fig.12 Relationship between the borehole enlargement rate and the relative fluid density

\section{Conclusion}

In the present work, investigation on the effects of drilling fluid density on both hydrate dissociation and borehole collapse around vertical borehole in hydrate-bearing sediments is conducted. The main results conclusions are as follows:

1) During drilling operation in hydrate reservoirs, effect of drilling fluid invasion on pore pressure is much greater than that on temperature. Pore pressure within almost the whole model has been affected at the end of the drill-

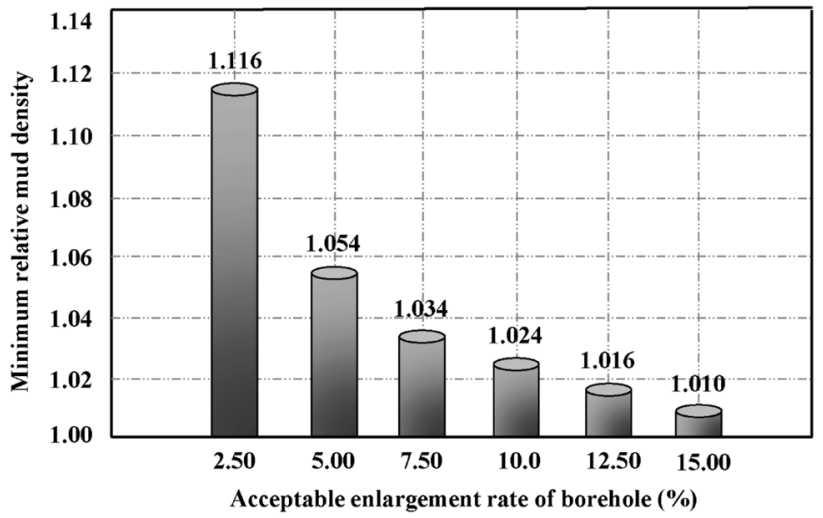

Fig.13 The minimum fluid weight when different acceptable borehole enlargement rates are defined

ing operation, whereas only the temperature within an annular area with a width of $0.506 \mathrm{~m}$ around wellbore is disturbed when drilling fluid temperature is $21.25^{\circ} \mathrm{C}$.

2) Hydrate dissociation occurs only in a portion of the reservoir that is disturbed by drilling fluid invasion around wellbore. Final range of hydrate dissociation is $12.08 \mathrm{~cm}$ when the pressure coefficient is 1.10 . The final dissociation range of natural gas hydrate increases with the decrease in bottom-hole pressure. It increases to $16.65 \mathrm{~cm}$ when the pressure coefficient of bottom-hole is increased to 0.98 .

3) Considering that borehole collapse in hydrate deposits is mainly caused by hydrate dissociation, it is an indisput- 
able fact that the drilling fluid density will also affect the borehole collapse. When the pressure coefficient is 0.98 , the borehole enlargement rate is $33.76 \%$. However, the borehole collapse caused by hydrate dissociation almost disappears when the pressure coefficient is increased to 1.10 .

4) The investigation herein can provide a method for determining the minimum fluid density in hydrate-bearing sediments with considering different acceptable borehole enlargement rates. For example, if the borehole enlargement rate of $2.5 \%$ is acceptable, the pressure coefficient of 1.116 can be viewed as the minimum fluid weight. However, the minimum fluid weight decreases with the increase in the acceptable borehole enlargement rate accordingly. The minimum fluid weight will decrease to 1.010 if the acceptable borehole enlargement rate is $15 \%$.

\section{Appendix A: USDFLD User subroutine}

C The user subroutine can realize the continuous change of physical parameters of hydrate bearing sediments with hydrate saturation between integration points.

C This source code provides all content including code and annotation in a relatively simple way. According to this source code, simulation of related engineering geological hazards during hydrate development can be realized by other researchers.

C USDFLD subroutine will be called at each node within the investigation model to automatically determine the physical parameters.

\section{SUBROUTINE USDFLD(FIELD,STATEV,PNEWDT ,DIRECT,T,CELENT, 1 TIME,DTIME,CMNAME,ORNAME,NFIELD,NST ATV,NOEL,NPT,LAYER, 2 KSPT,KSTEP,KINC,NDI,NSHR,COORD,JMAC,JM ATYP,MATLAYO,LACCFLA) \\ $\mathrm{C}$ \\ INCLUDE 'ABA_PARAM.INC' \\ $\mathrm{C}$ \\ CHARACTER $* 80$ CMNAME,ORNAME \\ CHARACTER*3 FLGRAY(15) \\ DIMENSION FIELD(NFIELD),STATEV(NSTATV), $\operatorname{DIRECT}(3,3), \mathrm{T}(3,3), \mathrm{TIME}(2)$ \\ DIMENSION ARRAY(15),JARRAY(15),JMAC(*),JM $\operatorname{ATYP}(*), \operatorname{COORD}(*)$}

$\mathrm{C}$ T1, Peq and POR1 herein are three real variables used to store the temperature, pressure and phase equilibrium pressure of each node.
REAL T1, Peq, POR1.

C According to the temperature of each node and Eq. (5), the phase equilibrium pressure of each node can be determined.

Peq $=10 * *(0.034 * \mathrm{~T} 1+0.0005 * \mathrm{~T} 1 * \mathrm{~T} 1+6.4804)$.

C According to the hydrate dissociation and saturation distribution, the simulation platform will automatically determine the spatial distribution of the sediment physical parameters according to Eqs. (1) to (4).

IF (POR1.GT.Peq) THEN.

$\operatorname{FIELD}(1)=2$.

ELSE

$\operatorname{FIELD}(1)=1$.

END IF

\section{RETURN}

END

C After that, ABAQUS will automatically perform subsequent borehole stability simulations based on the updated physical parameter distribution.

Acknowledgements This work is financially supported by the National Natural Science Foundation Project of China (51704311), the Qingdao National Laboratory for Marine Science and Technology (QNLM2016ORP0212), the Changiiang Scholars and Innovative Research Team in University (IRT_14R58), the National Natural Science Foundation Project of China (51504040), the National Basic Research Program of China (2015CB251201), the National Key Research and Development Program of China (2016YFC0304005), Postdoctoral Program of Henan Polytechnic University (712108/210) and the Shandong Provincial Natural Science Foundation, China (ZR2017BEE073).

Open Access This article is licensed under a Creative Commons Attribution 4.0 International License, which permits use, sharing, adaptation, distribution and reproduction in any medium or format, as long as you give appropriate credit to the original author(s) and the source, provide a link to the Creative Commons licence, and indicate if changes were made. The images or other third party material in this article are included in the article's Creative Commons licence, unless indicated otherwise in a credit line to the material. If material is not included in the article's Creative Commons licence and your intended use is not permitted by statutory regulation or exceeds the permitted use, you will need to obtain permission directly from the copyright holder. To view a copy of this licence, visit http://creativecommons.org/licenses/by/4.0/.

\section{References}

Cha Y, Yun TS, Kim YJ, Lee JY, Kwon T (2016) Geomechanical, hydraulic and thermal characteristics of deep oceanic sandy sediments recovered during the second ulleung basin gas hydrate 
expedition. Energies 9(10):775. https://doi.org/10.3390/en910 0775

Fereidounpour A, Vatani A (2014) An investigation of interaction of drilling fluids with gas hydrates in drilling hydrate bearing sediments. J Nat Gas Sci Eng 20:422-427. https://doi.org/10.1016/j. jngse.2014.07.006

Fereidounpour A, Vatani A (2015) Designing a polyacrylate drilling fluid system to improve wellbore stability in hydrate bearing sediments. J Nat Gas Sci Eng 26:921-926. https://doi.org/10.1016/j. jngse.2015.06.038

Gai XR, Sánchez M (2017) A geomechanical model for gas hydratebearing sediments. Environ Geotech 4(2):143-156. https://doi. org/10.1680/jenge. 15.00050

Klar A, Soga K, Ng MYA (2010) Coupled deformation-flow analysis for methane hydrate extraction. Géotechnique 60(10):765-776. https://doi.org/10.1680/geot.9.P.079-3799

Klar A, Uchida S, Soga K, Yamamoto K (2013) Explicitly coupled thermal flow mechanical formulation for gas-hydrate sediments. SPE J 18(2):196-206. https://doi.org/10.2118/162859-PA

Li QC, Cheng YF, Li Q, Wang FL, Zhang C, Yan CL (2018a) Investigation method of borehole collapse with the multi-field coupled model during drilling in clayey silt hydrate reservoirs. Frattura ed Integrità Strutturale 12(45):86-99. https://doi.org/10.3221/ IGF-ESIS.45.07

Li QC, Cheng YF, Li Q, Zhang C, Ansari U, Song BJ (2018) Establishment and evaluation of strength criterion for clayey silt hydrate bearing sediment. Energy Sources Part A Recov Util Environ Eff 40(6):742-750. https://doi.org/10.1080/15567036.2018.1457742

Li G, Li X, Zhang K, Li B, Zhang Y (2013) Effects of impermeable boundaries on gas production from hydrate accumulations in the Shenhu Area of the South China Sea. Energies 6:4078-4096. https://doi.org/10.3390/en6084078

Li G, Moridis GJ, Zhang K, Li XS (2011) The use of huff and puff method in a single horizontal well in gas production from marine gas hydrate deposits in the Shenhu Area of South China Sea. J Petrol Sci Eng 77:49-68. https://doi.org/10.1016/j.petrol.2011.02.009

Liu TL, Jiang GS, Zhang P, Sun JX, Sun HC, Wang R, Zheng MM (2016) A new low-cost drilling fluid for drilling in natural gas hydrate-bearing sediments. J Nat Gas Sci Eng 33:934-941. https:// doi.org/10.1016/j.jngse.2016.06.017

Liu J, Zhang J, Sun Y, Zhao T (2017) Gas hydrate reservoir parameter evaluation using logging data in the Shenhu area. South China Sea Nat Gas Geosci 28(1):164-172 ((in Chinese))

Lu S (2015) A global survey of gas hydrate development and reserves: specifically in the marine field. Renew Sust Energy Rev 41:884 900. https://doi.org/10.1016/j.rser.2014.08.063

Matsuda H, Yamakawa T, Sugai YC, Sasaki K (2016) Gas production from offshore methane hydrate layer and seabed subsidence by depressurization method. Engineering 8:353-364. https://doi.org/ 10.4236/eng.2016.86033

McConnell DR, Zhang ZJ, Boswell R (2012) Review of progress in evaluating gas hydrate drilling hazards. Mar Pertrol Geol 34:209_ 223. https://doi.org/10.1016/j.marpetgeo.2012.02.010

Mech P, Sangwai JS (2016) Effect of molecular weight of polyethylene glycol (PEG), a hydrate inhibitive water-based drilling fluid additive, on the formation and dissociation kinetics of methane hydrate. J Nat Gas Sci Eng 35:1441-1452. https://doi.org/10. 1016/j.jngse.2016.06.020

Merey S (2016) Drilling of gas hydrate reservoirs. J Nat Gas Sci Eng 35:1167-1179. https://doi.org/10.1016/j.jngse.2016.09.058

Milkov AV (2004) Global estimates of hydrate-bound gas in marine sediments: how much is really out there. Earth-Sci Rew 66(3):183-197. https://doi.org/10.1016/j.earscirev.2003.11.002

Nazridoust K, Ahmadi G (2007) Computational modeling of methane hydrate dissociation in a sandstone core. Chem Eng Sci 62(22):6155-6177. https://doi.org/10.1016/j.ces.2007.06.038
Ning FL, Wu NY, Yu YB, Zhang KN, Jiang GS, Zhang L, Sun JX, Zheng MM (2013) Invasion of drilling mud into gas-hydratebearing sediments. Part II: effects of geophysical properties of sediments. Geophys J Int 193(3):1385-1398. https://doi.org/10. 1093/gji/ggt016

Ning FL, Zhang KN, Wu NY, Zhang L, Li G, Jiang GS, Yu YB, Liu L, Qin YH (2013) Invasion of drilling mud into gas-hydrate-bearing sediments. Part I: effect of drilling mud properties. Geophys J Int 193(3):1370-1384. https://doi.org/10.1093/gji/ggt015

Qiu KB, Yamamoto K, Birchwood RA, Chen YR (2015) Well integrity evaluation for methane hydrate production in the deepwater Nankai Trough. SPE Drill Completion 30(1):52-67. https://doi. org/10.2523/IPTC-17792-MS

Rutqvist J, Moridis GJ (2007) Numerical studies on the geomechanical stability of hydrate-bearing sediments. SPE J 14(2):267-282. https://doi.org/10.2118/126129-PA

Sakamoto Y, Komai T, Miyazaki K, Tenma N, Yamaguchi T, Zyvoloski G (2010) Laboratory-scale experiments of the methane hydrate dissociation process in a porous media and numerical study for the estimation of permeability in methane hydrate reservoir. J Thermodyn. https://doi.org/10.1155/2010/452326

Sloan ED (1998) Clathrate hydrates of natural gases. Marcel Decker Inc, New York

Tan C P, Freij-Ayoub R, Clennell MB, Tohidi B, Yang J (2005) Managing wellbore instability risk in gas hydrate-bearing sediments. In: Proceeding of SPE Asia Pacific oil and gas conference and exhibition, Jakarta, Indonesia. https://doi.org/10.2118/92960-MS.

Uchida S, Soga K, Yamamoto K (2012) Critical state soil constitutive model for methane hydrate soil. J Geophys Res-Sol Ea 117(B3):3209-3221. https://doi.org/10.1029/2011JB008661

Wan ZF, Xu X, Wang XQ, Xia B, Sun YF (2017) Geothermal analysis of boreholes in the Shenhu gas hydrate drilling area, Northern South China Sea: influence of mud diapirs on hydrate occurrence. J Petrol Sci Eng 158:424-432. https://doi.org/10.1016/j.petrol. 2017.08.053

Wang X, Hutchinson D, Wu S, Yang S, Guo Y (2011) Elevated gas hydrate saturation within silt and silty clay sediments in the Shenhu area, South China Sea. J Geophys Res-Sol Ea 116(B5):B05102. https://doi.org/10.1029/2010JB007944

Wu SG, Wang JL (2018) On the China's successful gas production test from marine gas hydrate reservoirs. Chinese Sci Bull 63(1):2-8 ((in Chinese) $)$

Wu NY, Yang SX, Zhang H, Liang J, Wang H, Lu A (2010) Gas hydrate system of Shenhu Area, Northern South China Sea:Wireline Logging, Geochemical Results and Preliminary Resources Estimates. In: Proceedings of offshore technology conference, Houston, USA. https://doi.org/10.1155/2011/370298.

Xiao K, Zou C, Xiang B, Liu J (2013) Acoustic velocity log numerical simulation and saturation estimation of gas hydrate reservoir in Shenhu Area. South China Sea Sci World J 101459. https://doi. org/10.1155/2013/101459

Zhang W, Bai F, Shao M (2017) Tian Q (2017) Progress of offshore natural gas hydrate production tests in Japan and implication. Mar Geol Quat Geol 37(5):27-33 ((in Chinase))

Zhang HW, Cheng YF, Shi JH, Li LD, Li ML, Han XT, Yan CL (2017) Experimental study of water-based drilling fluid disturbance on natural gas hydrate-bearing sediments. J Nat Gas Sci Eng 47:1-10. https://doi.org/10.1016/j.jngse.2017.08.029

Zhao X, Qiu ZS, Huang WA (2015) Characterization of kinetics of hydrate formation in the presence of kinetic hydrate inhibitors during deepwater drilling. J Nat Gas Sci Eng 22:270-278. https:// doi.org/10.1016/j.jngse.2014.12.006

Zhao X, Qiu ZS, Zhang Z, Zhang YB (2020) Relationship between the gas hydrate suppression temperature and water activity in the presence of thermodynamic hydrate inhibitor. Fuel 264:116776. https://doi.org/10.1016/j.fuel.2019.116776

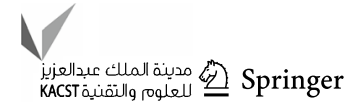


Zhao X, Qiu ZS, Zhao C, Xu JG, Zhang YB (2019) Inhibitory effect of water-based drilling fluid on methane hydrate dissociation. Chem Eng Sci 199:113-122. https://doi.org/10.1016/j.ces.2018.12.057
Publisher's Note Springer Nature remains neutral with regard to jurisdictional claims in published maps and institutional affiliations. 